\title{
Determinantes da Democracia: Novos Olhares sobre um Velho Debate
}

\author{
Adalberto de Lima*, Carlos Eduardo Gonçalves ${ }^{\dagger}$
}

Conteúdo: 1. Introdução; 2. Metodologia e Dados; 3. Resultados; 4. Conclusão.

Este artigo analisa a relação entre democracia e crescimento econômico para uma amostra de países no período entre 1950 e 2005. Utilizando modelos econométricos de duração, seus resultados apoiam a hipótese da modernização no sentido de que o regime democrático teria maior duração num país mais rico e educado. Porém, os resultados não apontam para uma redução da duração das ditaduras nos países de maior crescimento e população mais educada.

This paper studies the relationship between political regimes duration and growth using data for 1950-2005. Using econometric duration models to evaluate the so-called Modernization Hypothesis we find evidence supporting the idea that a democracy enjoys longer duration in richest and more educated countries. However, the duration of dictatorships does not seem to be affected by economic growth or the rise of educational attainment.

Palavras-chave: Democracia; Ditadura; Teoria da Modernização.

Códigos JEL: D72; 047.

\section{INTRODUÇÃO}

A discussão sobre a existência de uma relação entre desempenho econômico e regime político é antiga e se inicia com Lipset (1959), que argumenta ser o regime democrático a etapa final de um processo de modernização social e política dos países. Desenvolvimento causaria, portanto, a democracia. Tal proposição, que se difundiu na literatura sob o epíteto de Teoria da Modernização, deu vazão a uma ampla literatura empírica. Esse artigo se insere justamente nesse espaço, visando através de técnicas econométricas apropriadas testar os determinantes da duração de regimes democráticos e ditatoriais.

Przeworski e Fernando (1997) sugerem a possibilidade de duas formas de modernização: a endógena, segundo a qual o regime democrático emerge do processo de democratização conforme proposto por Lipset; e a exógena, segundo a qual a modernização não levaria o país à democracia, mas permitiria maior sobrevivência ao regime democrático, uma vez instaurado. Em sua análise empírica, a idéia da democratização endógena de Lipset é rejeitada.

*Doutor em Economia, FEA-USP. E-mail: adl302005@yahoo.com.br

${ }^{\dagger}$ Universidade de São Paulo, Departmento de Economia. E-mail: cesg@usp.br 
Barro (1999) investiga correlações entre um conjunto de variáveis econômicas - renda per capita, desigualdade de renda, classe média, fragmentação etnolinguística, nível e desigualdade educacional, fração religiosa - e um índice de medida de liberdade política para uma amostra de 100 países. Seus resultados indicam uma associação positiva entre o padrão de vida dos países e o índice de liberdade política. Também sugere que a propensão à democracia se reduz com a urbanização e com maior disponibilidade de recursos naturais. Sua evidência é, portanto, à primeira vista consistente com a tese de Lipset. Mais recentemente, contudo, Acemoglu et alii (2008) demonstram que as evidências que apóiam tal hipótese são muito fracas. Trabalhando com dois períodos de tempo, inicialmente o período padrão 1960-2000 e posteriormente um período mais longo 1875-2000, os autores não encontram evidências significativas para a relação causal entre renda per capita e democracia em estimações em painel controlando para efeitos fixos.

Inserindo-se neste debate, o presente artigo propõe o uso de modelos não lineares para dados censurados (modelos de sobrevivência) para avaliar o impacto de variáveis econômicas sobre a duração dos regimes democráticos e ditatoriais numa amostra de 189 países, no período de 1950 a 2005 . 0 objetivo aqui é determinar se países mais modernos no sentido de Lipset ofereceriam um terreno mais fértil para regimes democráticos, ao passo que em países mais pobres e "atrasados" os regimes ditatoriais apresentariam maior resistência ao colapso. Os resultados sugerem apoio à teoria da modernização na vertente da democratização exógena anteriormente mencionada. Encontra-se que uma vez instaurado o regime democrático em um país, este terá maior sobrevivência no caso de uma nação rica e com população mais educada. Por outro lado, um regime ditatorial não apresenta menor sobrevivência num país mais "moderno" no sentido de Lipset, contradizendo a hipótese de democratização endógena. Adicionalmente a democracia apresenta menor sobrevivência em países onde a agricultura possui maior participação no produto, na direção do sugerido por Acemoglu e James (2006).

\section{METODOLOGIA E DADOS}

Essa seção descreve brevemente o método de estimação aqui empregado ${ }^{1}$ e o conjunto de dados usados.

Tome-se a duração ("vida") de um regime político qualquer por $T$, variável que apresenta uma função de distribuição, $F(t)=P(T \leq t)$, na população sob análise. $O$ interesse aqui é estimar a probabilidade de um certo país deixar o regime político no qual se encontra num dado instante $t$. Esta probabilidade é dada por $P(t<T \leq t+h \mid T>t)$. A hazard-rate associada é, por sua vez:

$$
\lambda_{t}=\lim _{h \rightarrow 0} \frac{P(t<T \leq t+h \mid T>t)}{h} .
$$

Adicionando um vetor $X(t)$ de regressores no período $t$ descrevendo um conjunto de características relevantes da população, a hazard rate de interesse pass a ser dada por:

$$
\lambda_{t}(X)=\lim _{h \rightarrow 0} \frac{P(t<T \leq t+h \mid T>t ; X)}{h} .
$$

Para a estimação, divide-se a linha de tempo da amostra em $M+1$ intervalos $\left[0, a_{1}\right), \ldots,\left[a_{m}, \infty\right)$, onde cada $a_{i}$ é um instante específico de tempo. O último intervalo é escolhido de forma que qualquer duração que caia nele seja censurada em $a_{m}$. Para cada país da amostra, $c_{m}$ é um indicador binário que assume valor 1 se a duração for censurada no intervalo $m$, e zero caso contrário. Obviamente, se

\footnotetext{
${ }^{1}$ Para maiores detalhes, ver Wooldridge (2002).
} 
$c_{m}=1, c_{m+1}=1$, ou seja, se a duração foi censurada em algum intervalo ela permanece censurada para os intervalos subsequentes.

Similarmente, $y_{m}$ é um indicador binário que assume valor 1 se a duração do regime no qual daquele país terminar no intervalo $m$ e zero caso contrário. Se a duração é censurada no intervalo $m$ com $c_{m}=1$, então $y_{m}=1$ por convenção. Por fim, um conjunto de dummies é utilizado para indicar o intervalo no qual o país entra na amostra. A informação relevante é o intervalo no qual $y_{i m}$ assume valor 1 pela primeira vez, o que representa a mudança no regime político ou censura.

Para cada país tem-se $X_{i}=\{x, \ldots, x\}_{i}$ vetores de covariáveis observados em cada intervalo de tempo e assumidos constantes dentro do intervalo. Considera-se que o risco e a censura, em cada período de tempo $t$ condicional a covariáveis em $t$, dependem apenas dos valores das covariáveis em $t$. Se uma observação é censurada no intervalo $m$, a informação sobre a duração é contida em $y_{11}=0, \ldots y_{i m-1}=$ 0 . Para o país que mudar de regime político no intervalo $m$ existirá a informação adicional em $y_{i m}=1$. A partir daí constrói-se a função log verossimilhança parcial (Wooldridge, 2002).

Para a implementação da MLE parcial, será necessária uma especificação da função de risco. Por simplicidade, assume-se aqui a especificação comumente empregada de uma função de risco piece-wise constant, $\lambda(t ; x ; \theta)=v . \varkappa(\beta x ; \theta) . \lambda_{m}$.

Os parâmetros a serem estimados são $\beta$ e $\lambda$. Como os $\lambda_{m}$ não são restritos, $x$ não contém intercepto, e $v>0$ é o termo de heterogeneidade, continuamente distribuído.

A seleção dos episódios de democracia e ditadura foi feita à semelhança de Persson e Tabellini (2009). Em cada período de tempo, os países que apresentaram score positivo no índice de liberdade política Polity 2 do Polity IV Project ${ }^{2}$ foram qualificados como democracias, enquanto os países com score negativo ditaduras. Identificou-se, assim, 140 episódios de ditadura e 157 de democracia entre 1950 e 2005. Como covariáveis foram utilizadas PIB per capita, taxa de crescimento econômico, e grau de abertura econômica (exportações mais importações como proporção do PIB) da Penn Worlds Tables 6.1; taxa de urbanização do World Bank (2005); ${ }^{3}$ e dados de educação - anos de escolaridade da população - de Barro e Lee (2000). A variável de controle "crise" indica períodos no qual o país está sob crise econômica ou política. Um país foi considerado em crise econômica se exibiu crescimento econômico negativo no período associado. Foi considerado em crise política se apresentou um interregno ou regime de transição no período. A variável "crise" foi calculada como a razão entre os anos de crise econômica e política e o numero de anos que o país aparece na amostra. Um baixo valor para essa variável indica um país que esteve pouco sujeito a crises no período analisado.

\section{RESULTADOS}

A primeira análise é referente à teoria da modernização. São apresentadas as estimativas para os modelos Weibul e piecewise-constant para democracias (Tabela 1) e para ditaduras (Tabela 2). Observa-se que no caso das democracias, apenas o PIB per capita mostrou-se significante, com coeficiente bastante próximo nos dois modelos. $O$ valor de $-0,30$ para seu coeficiente indica que, tudo o mais constante, uma elevação de US\$ 1.000 do PIB per capita do país num período de cinco anos estaria associada a uma probabilidade $25 \%$ menor de colapso do regime democrático no mesmo período, em média.

A Tabela 2 mostra que para os períodos de ditadura, apenas a constante é estatisticamente significante. Não encontramos aqui, portanto, evidências para a tese da modernização endógena de Lipset.

\footnotetext{
${ }^{2}$ http://www.systemicpeace.org/polity/polity4.htm

${ }^{3}$ http://data.worldbank.org/
} 
Tabela 1: Variável dependente: Duração das Democracias

\begin{tabular}{lcc}
\hline Variável Explicativa & Weibull & Piecewise-constant \\
\hline $1-\alpha$ & -0.56 & - \\
& $(0.42)$ & - \\
PIB per capita & $-0.30^{* * *}$ & $-0.38^{* * *}$ \\
& $(0.11)$ & $(0.14)$ \\
Urbanização & 0.00 & -0.08 \\
& $(0.01)$ & 0.14 \\
Escolaridade & -0.13 & 0.01 \\
& $(0.13)$ & 0.02 \\
Constante & -0.24 & - \\
& $(0.81)$ & - \\
\hline
\end{tabular}

*** Significante ao nível de $1 \%$.

Desvios padrões ente parênteses.

Tabela 2: Variável dependente: Duração das Ditaduras

\begin{tabular}{lc}
\hline Variável Explicativa & Weibull \\
\hline $1-\alpha$ & $5.87^{* *}$ \\
& $(2.60)$ \\
PIB per capita & -0.11 \\
& $(0.12)$ \\
Urbanização & 0.02 \\
& $(0.02)$ \\
Escolaridade & 0.30 \\
& $(0.18)$ \\
Constante & $-14.86^{* * *}$ \\
& $(5.55)$ \\
$\theta$ & 2.30 \\
& $(1.81)$ \\
\hline *** Significante ao nível de $1 \%$. \\
** Significante ao nível de $5 \%$. \\
\multicolumn{2}{c}{ Desvios padrões entre parentêsis. }
\end{tabular}


Já na Tabela 3 testam-se os argumentos de Acemoglu e James (2006) sobre o impacto de crises e composição do PIB sobre a probabilidade de colapso de um regime ditatorial. A variável "crise" mostrase significante e com sinal positivo, indicando que crises econômicas e/ou políticas elevam o risco de colapso do regime democrático - o que é bastante intuitivo. O modelo piecewise-constant aponta para uma relação entre a participação da agricultura no PIB do país e a duração do regime democrático, mas esse efeito não é muito robusto à especificação.

Tabela 3: Variável dependente: Duração das Democracias

\begin{tabular}{lcc}
\hline Variável Explicativa & Weibull & Piecewise-constant \\
\hline $1-\alpha$ & -2.50 & \\
& $(0.82)$ & \\
Abertura & 0.01 & $0.01^{* *}$ \\
& $(0.01)$ & $(0.01)$ \\
PIB Agrícola & 0.04 & $0.06^{* *}$ \\
& $(0.02)$ & 0.03 \\
Crise & $0.06^{* *}$ & $0.06^{* *}$ \\
& $(0.02)$ & $(0.02)$ \\
Desigualdade & -0.03 & -0.05 \\
& $(0.04)$ & $(0.05)$ \\
Constante & 0.66 & \\
& $(2.43)$ \\
*** Significante ao nível de 1\%. \\
** Significante ao nível de 5\%. \\
Desvios padrões entre parentêsis.
\end{tabular}

\section{CONCLUSÃO}

Utilizando modelos econométricos de sobrevivência este artigo encontrou evidências que confirmam a teoria da modernização, dentro do princípio de democratização exógena. Assim, o regime democrático ao ser instaurado num país com maior PIB per capita e maior nível educacional tem maior sobrevivência que se instaurado num país sem estas características. Rejeita, entretanto, o princípio de democratização endógena, pois não encontra evidência significativa de que a modernização do país tenha efeito sobre a duração dos períodos sob regime ditatorial 


\section{BIBLIOGRAFIA}

Acemoglu, D. \& James, R. (2006). Economic Origins of Dictatorship and Democracy. Cambridge: University Press.

Acemoglu, D., Simon, J., J., R., \& Yared, P. (2008). Income and democracy. American Economic Review, 98(3):808-842.

Barro, R. (1999). The determinants of democracy. Journal of Political Economy, 107:158-183.

Barro, R. J. \& Lee, J. (2000). International data on educational attainment: Updates and implications. NBER Working Papers, 7911.

Lipset, S. (1959). Some social requisites of democracy: Economic development and political legitimacy. American Political Science Review, 53:69-105.

Persson, T. \& Tabellini, G. (2009). Democratic capital: The nexus of political and economic change. American Economic Journal, 1(2):88-126.

Przeworski, A. \& Fernando, L. (1997). Modernization: Theory and facts. World Politics, 49:155-183.

Wooldridge, J. (2002). Econometric analysis of cross section and panel data. The MIT Press, Cambridge, MA.

World Bank (2005). World Development Indicators. http://data.worldbank.org/data-catalog/worlddevelopment-indicators. 